\title{
O OLHAR SOCIAL DAS CADEIAS DE SUPRIMENTO: UMA REVISÃO INTEGRATIVA DA LITERATURA
}

\author{
Renato Barros Leite* \\ Ericê Bezerra Correia* \\ Claudia Daniele Barros Leite-Salgueiro****
}

RESUMO: O objetivo deste estudo foi realizar uma revisão da literatura das pesquisas brasileiras de sustentabilidade em cadeias de suprimento com foco nas questões sociais. Trata-se de uma Revisão Integrativa da literatura para o período de 2008 a 2017, utilizando as palavras-chave: Gestão das Cadeias de Suprimento; Cadeias Suprimento; Gestão da Sustentabilidade em Cadeias de Suprimentos; Sustentabilidade em Cadeias de Suprimento; Sustentabilidade; Dimensão Social; Triple Bottom Line e, auxiliados com o uso da base de dados Scientific Periodicals Electronic Library (SPELL), cuja produção está concentrada nas áreas da Administração, Contabilidade e Turismo. Entre as questões sociais discutidas nos artigos estão: 1) benefícios sociais sobre os valores humanos (qualidade de vida, igualdade de acesso aos serviços sociais, distribuição de renda, entre outros); 2) práticas de responsabilidade social empresarial (balanço social, código de ética, entre outros); e 3) aspectos gerais da SSCM e as questões sociais. A revisão integrativa da literatura aponta para a necessidade de serem discutidos os efeitos das questões sociais em cadeias de suprimento, visto que o desenvolvimento da SSCM só ocorrerá com a difusão de novas investigações e pesquisas materializados em periódicos nacional e internacional.

PALAVRAS-CHAVE: Cadeias de Suprimento; Dimensão Social; Revisão Integrativa; Sustentabilidade.

\section{A SOCIAL GLANCE ON SUPPLY CHAINS: AN INTEGRATIVE REVIEW OF THE LITERATURE}

\footnotetext{
ABSTRACT: A review of the literature on Brazilian research on sustainability in supply chains focusing on social issues is provided. Current integrative review of the

Doutorando em Administração de Empresas na Universidade de Fortaleza (UNIFOR). Docente Assistente da Faculdade de Ciências Humanas e Sociais Aplicadas do Cabo de Sto. Agostinho (FACHUCA), Brasil.

E-mail: renatobarrosleite@hotmail.com

** Pós-Doutor em Innovation in Regional Development pela University of Aveiro - Portugal. Docente do Mestrado de Gestão do Desenvolvimento Local Sustentável da Universidade de Pernambuco (UPE), Brasil.

*** Psicóloga. Doutoranda em Psicologia Clínica pela Universidade Católica de Pernambuco (UNICAP). Docente do Instituto Federal de Educação, Ciência e Tecnologia de Pernambuco (IFPE), Brasil.
} 
literature for 2008-2017 employs the keywords Management of Supply Chains, Supply Chains, Sustainability Management, Social Dimension and Triple Bottom Line. Scientific Periodicals Electronic Library (SPELL), concentrating on Administration, Accounting and Tourism, was employed. Social issues in the articles comprised: 1) social benefits on human values (life quality, equality in access to social services, income distribution and others); 2) entrepreneur social responsibility (social balance, ethic code and others); and 3) general aspects of SSCM and social issues. The integrative review of the literature shows an urgent need to discuss the effects of social issues in supply chains. In fact, the development of SSCM occurs only when new investigation and research in national and international journals are disseminated.

KEY WORDS: Supply chain; Social dimension; Integrative review; Sustainability.

\section{INTRODUÇÃO}

Os estudos de sustentabilidade em cadeias de suprimento têm se debruçado nas premissas do Triple Bottom Line (TBL) de Elkington (2002) e suas dimensões: econômica, social e ambiental. Sabe-se que as preocupações, ou melhor, as bases para o que se convencionou chamar de desenvolvimento sustentável surgem do embate político segurado em décadas de conferências, que trataram especificamente das questões ambientais. É notório que a definição de desenvolvimento sustentável (DS) que mais repercutiu foi a do chamado relatório de Brundtland concebido em 1987, a partir do documento intitulado "Nosso futuro comum".

O DS é um tema bastante complexo por encontrar-se na fronteira do conhecimento da transdisciplinaridade, capaz de influenciar novas pesquisas acadêmicas, reformular políticas públicas já existentes, modificar processos produtivos vigentes, bem como os atuais modelos de negócios (LINTON et al., 2007; SILVA; NASCIMENTO, 2016). É preciso transparecer os reais interesses e interessados desse desenvolvimento sustentável. Para que o DS avance é necessário respeitar as singularidades do tema, as possíveis interações entre as diversas abordagens e a coerência do tema dentro do contexto de pesquisa (SILVA; NASCIMENTO, 2016).

A cadeia de suprimento, por exemplo, é um tema amplo que não se prende unicamente a uma teoria. A compreensão do conceito requer a investigação de di- 
ferentes princípios e definições. A relação entre cadeia de suprimento e as questões ambientais vem ganhando espaço desde a década de 1990 com os mais variados temas: gestão ambiental da cadeia de suprimento (Supply Chain Environmental Management, SCEM), gestão da cadeia de suprimento ambiental (Environmental Supply Chain Management, ESCM), gestão da cadeia de suprimento verde (Green Supply Chain Management, GSCM), e cadeias de suprimento de ciclo-fechado (Closed-loop Supply Chain, CLSC). Estes termos trazem significado às preocupações ambientais, ou melhor, se restringem apenas às dimensões econômicas e ambientais (CARVALHO; BARBIERI, 2013).

Com a inclusão do termo Sustainable Supply Chain Management (SSCM), traduzido por Silva (2017) como Sustentabilidade em Cadeias de Suprimentos (SCM), foi introduzida a dimensão social nos estudos de Gestão da Cadeia de Suprimento ou Supply Chain Management (SCM), com destaque para os trabalhos de Linton et al. (2007); Carter; Rogers (2008); Seuring (2008); Seuring; Müller (2008); Pagell; Wu (2009), que fizeram críticas à ênfase dada pelos trabalhos anteriores em relação aos temas performance e gerenciamento de risco, soma-se ainda a necessidade de distinção das dimensões da sustentabilidade, que passou a ser possível graças a convergência do TBL à SCM (CARVALHO; BARBIERI, 2013; TOUBOLIC; WALKER, 2015; ALVES; SILVA, 2017).

O Triplo Bottom Line proposto em 1994 obteve uma posição de destaque só no final da década de 1990, com os resultados de uma pesquisa conduzida por especialistas internacionais em responsabilidade social corporativa (RSC) e desenvolvimento sustentável (DS). Já em 1995, foram formulados os 3P, "pessoas, planeta e preço (lucros)", esses 3P integraram o primeiro Relatório da Shell, e posteiormente tal conceito passou a ser amplamente utilizado na Holanda como 3Ps. Em síntese, a agenda do TBL está concentrada nas empresas, contudo, trata-se de uma abordagem que além de considerar a dimensão econômica agrega outras duas dimensões, ambiental e social (ELKINGTON, 2002).

Dessa convergência do TBL a SCM são discutidos os primeiros passos para a sustentabilidade, que se encontra intrínseca ao comportamento das pessoas quanto ao ato de escolher ou decidir sobre a aquisição de produtos e serviços ofertados pelas empresas, além do que, os consumidores execem forte pressão sobre os negó- 
cios das empresas no que diz respeito às questões ambientais (ELKINGTON, 2002). Assim como no TBL, ainda não se sabe ao certo a abrangência desses conceitos individualmente, logo ao deparar com a convergência desses dois conceitos amplia-se ainda mais a necessidade de se investigar outras visões relacionadas ao tema da SCM para além do foco deste artigo que tem como recorte de pesquisa as publicações nacionais em SCM com ênfase na dimensão social.

Ante ao exposto, o objetivo do artigo é realizar uma revisão integrativa da literatura das pesquisas brasileiras de sustentabilidade em cadeias de suprimento com foco nas questões sociais. Tal objetivo é justificado pela preocupação de harmonizar todas as três dimensões do TBL, pois não é possível que diante das pressões exercidas pelas partes interessadas externas (Mídias, ONGs, Sociedade civil, consumidores), empresas ainda ousem continuar envolvidas em escândalos relacionados ao trabalho escravo e infantil, entre outros que estão sob a tutela dos direitos humanos, práticas antiéticas ou socialmente inaceitáveis (ALVES; SILVA, 2017; YAWAR; SEURING, 2015).

Para melhor compreensão do estudo, além desta introdução foram estruturadas as seguintes seções: metodologia, resultados e discussão, considerações finais.

\section{METODOLOGIA}

Com a finalidade de diminuir as limitações analíticas frequentes nas pesquisas qualitativas, foi proposto para o artigo o método da revisão integrativa da literatura. "É um método que tem a finalidade de sintetizar resultados obtidos em pesquisas sobre um delimitado tema ou questão, de maneira sistemática e ordenada, com o objetivo de contribuir para o conhecimento desse tema ou questão [...]" (ROMAN; FRIEDLANDER, 1998, p. 109).

No caso específico das metodologias e técnicas de pesquisa convencionalmente denominadas de qualitativas, parte das dificuldades em abordá-las analiticamente decorre de sua grande fluidez, imprecisão e maleabilidade no que diz respeito tanto aos suportes teóricos e epistemológicos quanto às diversas formas de sua aplicação: abarcam processos diferenciados de levantamento, registro e tratamento de material empírico (COLBARI, 2014, p. 241). 
Por conseguinte, trata-se de um método cujos instrumentos de levantamento, registro e tratamento de material já se encontram validados. Nesse domínio, a revisão integrativa permite a inclusão de diversos métodos e técnicas, conforme: Processo de seleção dos estudos (Fluxograma) e Checklist do Preferred Reporting for Systematic Reviews and Meta-Analyses (THE PRISMA STATEMENT; MOHER, 2015). Para a coleta dos dados, agrupamento e análise dos trabalhos, existe à disposição o formulário validado por URSI (2005) (ROMAN; FRIEDLANDER, 1998; SOUZA et al., 2010; BERNADES; PEGORARO, 2015; MOREIRA et al., 2015; ANDRADE PEREZ et al., 2016; FRANÇA et al., 2016).

Para instrumentalizar as pesquisas de revisão integrativa, tem-se utilizado as seis fases propostas por Ganong (1987) e Cooper (1982; 1989). No Brasil, se destacam os trabalhos de Roman; Friedlander (1998); Souza et al. (2010); e Bernades; Pegoraro (2015) como base para alcançar o método. Conforme citado por esses autores brasileiros na primeira fase, elabora-se a pergunta norteadora, a partir dessa pergunta são selecionadas as perguntas-chave que serão introduzidas na segunda fase da pesquisa, com a escolha das bases de dados indexadas, utilizadas para seleção do material que irá responder a pergunta de pesquisa.

O exame do material é realizado durante a terceira fase, onde é extraído o conteúdo do material selecionado, para que, na quarta fase, o pesquisador possa executar uma análise crítica dos estudos da amostra. Na quinta fase, são discutidos os resultados justapondo as literaturas selecionadas, onde é possível identificar lacunas, vieses e oportunidades para discussões futuras do tema. Por fim, a sexta fase, que incide na apresentação.

A confluência entre as seis fases da pesquisa decorre da definição da pergunta norteadora. "A definição da pergunta norteadora é a fase mais importante da revisão, pois determinam quais serão os estudos incluídos, os meios adotados para a identificação e as informações coletadas de cada estudo selecionado" (SOUZA et al., 2010, p. 104). No caso do presente, foi definida a seguinte pergunta norteadora: "Como as pesquisas brasileiras de sustentabilidade em cadeias de suprimento com foco na dimensão social estão sendo caracterizadas?"

Para seleção dos estudos, foi utilizada a seguinte base de dados: Scientific Periodicals Electronic Library (SPELL), que tem concentrado os esforços de produ- 
ção das principais publicações brasileiras nas áreas de Administração, Contabilidade e Turismo. Tais estudos foram destacados pela busca isolada ou do cruzamento das palavras-chave: Gestão da Cadeia de Suprimento; Cadeia Suprimento; Gestão da Sustentabilidade em Cadeia de Suprimento; Sustentabilidade em Cadeia de Suprimento; Sustentabilidade; Dimensão Social; Triple Bottom Line, em português e inglês. Como critério de inclusão: estudos nacionais completos publicados no período de 2008 a 2017, conforme a fase de consolidação dos estudos em SSCM entre os anos de 2008 e 2013 (YAWAR; SEURING, 2015).

Destarte, faz-se mister expor que a metodologia proposta é bastante presente em estudos das ciências da saúde, especificamente, nas áreas de medicina e enfermagem, todavia, menos presente em estudos das ciências sociais aplicadas como a administração, por exemplo, repercutindo, neste sentido, no caráter inovador do estudo ora proposto.

\section{RESULTADOS E DISCUSSÃO}

A seleção dos artigos contou com a resposta da pergunta norteadora mais as etapas do fluxograma PRISMA Statement, tais quais: identificação, seleção, elegibilidade e inclusão. Para a etapa de identificação foram encontrados na base de dados SPELL um total de 20 artigos, desses um era duplicado, restando 19 artigos. Na etapa de seleção após leitura dos títulos foi excluído 1 artigo e outros 9 foram excluídos, a partir da leitura dos resumos. A elegibilidade dos artigos contou com a leitura integral dos trabalhos, onde foram excluídos 11 artigos após a leitura integral. Por fim, a etapa de inclusão contou com a seleção de 6 artigos. Na Figura 1 estão representadas todas as etapas do processo de seleção dos artigos. 


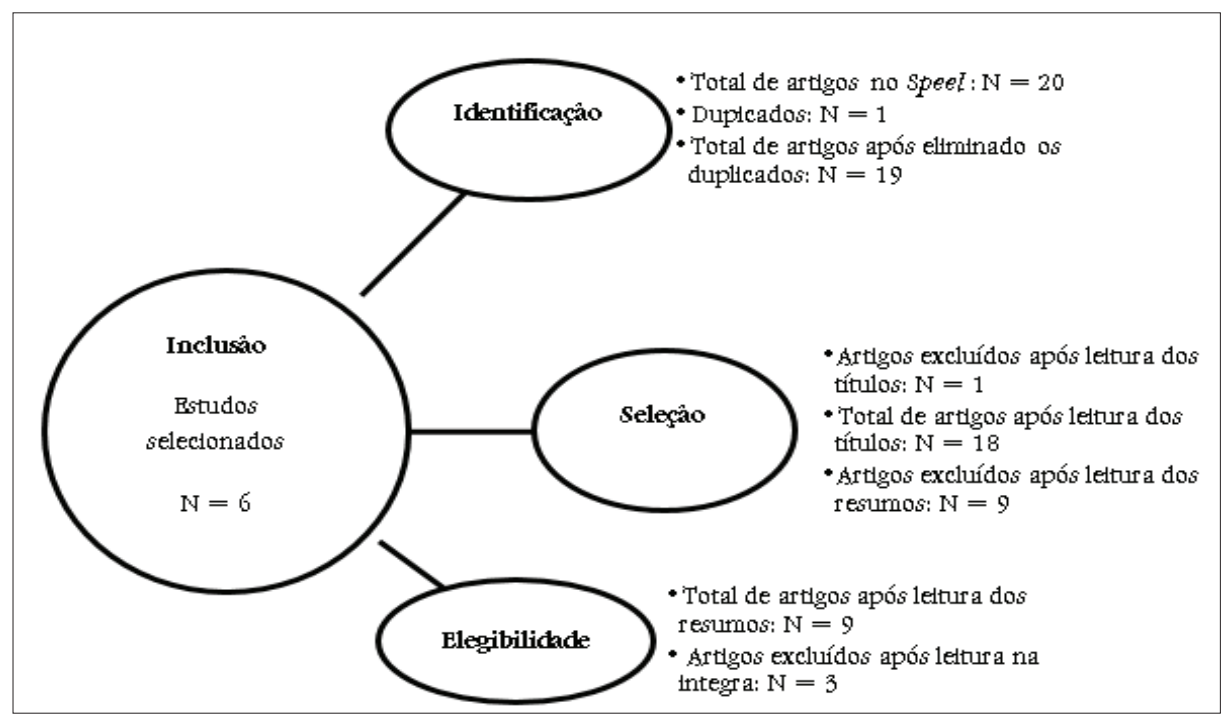

Figura 1. Fluxograma dos critérios de seleção dos artigos de acordo com o PRISMA Statement (2015).

A síntese dos resultados encontra-se caracterizada no Quadro 1, com as informações sobre o periódico, ano, título, autor, tipo de estudo, objetivo e conclusão. 
Quadro 1. Apresentação das características centrais dos artigos selecionados

(Continua)

\begin{tabular}{|c|c|c|c|}
\hline Periódico & \multirow{4}{*}{$\begin{array}{l}\text { Título } \\
\text { Tipo de estudo }\end{array}$} & \multirow{4}{*}{ Objetivo } & \multirow{4}{*}{ Conclusão } \\
\hline Ano & & & \\
\hline País & & & \\
\hline Autoria & & & \\
\hline $\begin{array}{l}\text { Gestão e Sociedade } \\
2017 \\
\text { Brasil } \\
\text { P.1. DROHOMERETSKI, } \\
\text { E.; } \\
\text { CUNHA, A. R.; } \\
\text { ECKSTEIN, C. M. C.; } \\
\text { MACEDO, E. D. J.; } \\
\text { DE OLIVEIRA, O. M. }\end{array}$ & $\begin{array}{l}\text { Os Impactos da Logística } \\
\text { Reversa Social em uma } \\
\text { Cadeia de Suprimentos } \\
\text { do Setor de Papel da } \\
\text { Grande Curitiba. } \\
\text { Abordagem Qualitativa } \\
\text { (Estudo de caso múlti- } \\
\text { plo). }\end{array}$ & $\begin{array}{l}\text { Analisar os } \\
\text { impactos da } \\
\text { Logística Re- } \\
\text { versa Social em } \\
\text { uma cadeia de } \\
\text { suprimentos do } \\
\text { setor de papel } \\
\text { em Curitiba e } \\
\text { Região Metro- } \\
\text { politana. }\end{array}$ & $\begin{array}{l}\text { A partir da sanção da } \\
\text { Lei } 12.305 / 10 \text { é possível } \\
\text { afirmar que as empresas } \\
\text { investigadas, dentre out- } \\
\text { ras, passaram a comun- } \\
\text { gar do objetivo comum } \\
\text { de reduzir o impacto } \\
\text { ambiental inerente aos } \\
\text { seus resíduos, bem } \\
\text { como impulsionar o } \\
\text { aumento da valorização } \\
\text { social entre os colabora- } \\
\text { dores e a comunidade } \\
\text { local. }\end{array}$ \\
\hline $\begin{array}{l}\text { Gestão Ambiental e } \\
\text { Sustentabilidade } \\
2017 \\
\text { Brasil } \\
\text { P.2. ALVES, A. P. F.; DA } \\
\text { SILVA, M. E. }\end{array}$ & $\begin{array}{l}\text { Reflexões Empíricas } \\
\text { Sobre a Dimensão Social } \\
\text { da Sustentabilidade em } \\
\text { Cadeias de Suprimento: } \\
\text { O que Precisa Mudar? } \\
\text { Abordagem Qualitativa } \\
\text { (Estudo de caso único). }\end{array}$ & $\begin{array}{l}\text { Identificar a } \\
\text { aplicação de } \\
\text { aspectos sociais } \\
\text { na cadeia de } \\
\text { suprimento de } \\
\text { uma empresa } \\
\text { de confecções } \\
\text { brasileira. }\end{array}$ & $\begin{array}{l}\text { O objetivo proposto foi } \\
\text { alcançado por destacar } \\
\text { alguns dos aspectos } \\
\text { elencados ao longo de } \\
\text { uma cadeia de supri- } \\
\text { mentos investigada. }\end{array}$ \\
\hline $\begin{array}{l}\text { Journal of Operations } \\
\text { and Supply Chain Man- } \\
\text { agement } \\
2017 \\
\text { Brasil } \\
\text { P.3. SILVA, M. E.; FRITZ, } \\
\text { M. M.; NUNES, B. }\end{array}$ & $\begin{array}{l}\text { Scanning insights on } \\
\text { sustainability and supply } \\
\text { chain management in } \\
\text { Brazil. } \\
\text { Abordagem Qualitativa } \\
\text { (Revisão da Literatura } \\
\text { fundamentada com a } \\
\text { perspectiva dos especia- } \\
\text { listas). }\end{array}$ & $\begin{array}{l}\text { Analisar as } \\
\text { publicações } \\
\text { científicas e as } \\
\text { perspectivas } \\
\text { dos especialis- } \\
\text { tas para ampliar } \\
\text { o espectro e } \\
\text { traçar uma } \\
\text { compreensão } \\
\text { mais ampla da } \\
\text { sustentabili- } \\
\text { dade e gestão } \\
\text { da cadeia de } \\
\text { suprimentos no } \\
\text { Brasil. }\end{array}$ & $\begin{array}{l}\text { Constatou-se um } \\
\text { significativo aumento } \\
\text { das pesquisas sobre esta } \\
\text { temática; assim como } \\
\text { ocorre em outros países } \\
\text { as questões sociais não } \\
\text { são o foco na maioria } \\
\text { dos trabalhos. }\end{array}$ \\
\hline
\end{tabular}


(Continua)

\begin{tabular}{|c|c|c|c|}
\hline Periódico & \multirow{4}{*}{$\begin{array}{l}\text { Título } \\
\text { Tipo de estudo }\end{array}$} & \multirow{4}{*}{ Objetivo } & \multirow{4}{*}{ Conclusão } \\
\hline Ano & & & \\
\hline País & & & \\
\hline Autoria & & & \\
\hline $\begin{array}{l}\text { Journal of Operations } \\
\text { and Supply Chain Man- } \\
\text { agement } \\
2015 \\
\text { Brasil } \\
\text { P.4. SILVA, M. E.; NEUT- } \\
\text { ZLING, D. M.; ALVES, A. } \\
\text { P. F.; DIAS, P.; SANTOS, } \\
\text { C. A. F. D.; NASCIMEN- } \\
\text { TO, L. F. }\end{array}$ & $\begin{array}{l}\text { Sustainable Supply } \\
\text { Chain Management: a } \\
\text { Literature review on } \\
\text { Brazilian publications. } \\
\text { Abordagem Qualitativa } \\
\text { (Revisão da literatura). }\end{array}$ & $\begin{array}{l}\text { O artigo } \\
\text { pretende } \\
\text { analisar como } \\
\text { o conceito de } \\
\text { Sustentabili- } \\
\text { dade em Cadeia } \\
\text { de Suprimento } \\
\text { foi explorado } \\
\text { em artigos } \\
\text { publicados em } \\
\text { grandes revistas } \\
\text { brasileiras e } \\
\text { trabalhos de } \\
\text { conferências, } \\
\text { especialmente } \\
\text { no que se } \\
\text { refere às áreas } \\
\text { de pesquisa de } \\
\text { gerenciamento } \\
\text { de operações } \\
\text { e sustentabili- } \\
\text { dade. }\end{array}$ & $\begin{array}{l}\text { Não se sabe ao certo } \\
\text { a contribuição efetiva } \\
\text { da Sustainable Supply } \\
\text { Chain Management. } \\
\text { É preciso que sejam } \\
\text { investigadas aplicações } \\
\text { empíricas sobre o tema } \\
\text { de modo que se possa } \\
\text { contribuir para as } \\
\text { discussões acadêmicas. }\end{array}$ \\
\hline
\end{tabular}


(Conclusão)

\begin{tabular}{|c|c|c|c|}
\hline Periódico & \multirow{4}{*}{$\begin{array}{l}\text { Título } \\
\text { Tipo de estudo }\end{array}$} & \multirow{4}{*}{ Objetivo } & \multirow{4}{*}{ Conclusão } \\
\hline Ano & & & \\
\hline País & & & \\
\hline Autoria & & & \\
\hline $\begin{array}{l}\text { Journal of Operations } \\
\text { and } \\
\text { Supply Chain Manage- } \\
\text { ment. } \\
2014 \\
\text { Brasil } \\
\text { P.5. ABDALA, E. C.; } \\
\text { BARBIERI, J. C. }\end{array}$ & $\begin{array}{l}\text { Determinants of Sustain- } \\
\text { able Supply Chain: an } \\
\text { Analysis of Mensuration } \\
\text { Models of Pressures and } \\
\text { Socio Environmental } \\
\text { Practices. } \\
\text { Abordagem Quantitativa } \\
\text { (Estatística descritiva, } \\
\text { análise fatorial explora- } \\
\text { tória e confirmatória). }\end{array}$ & $\begin{array}{l}\text { Compreender } \\
\text { os fatores } \\
\text { determinantes } \\
\text { das pressões } \\
\text { e práticas } \\
\text { ambientais no } \\
\text { gerenciamento } \\
\text { da cadeia de } \\
\text { suprimento } \\
\text { sustentável, a } \\
\text { partir do desen- } \\
\text { volvimento de } \\
\text { dois modelos } \\
\text { de medição: } \\
\text { 1) pressões } \\
\text { e 2) práticas } \\
\text { socioambientais } \\
\text { realizadas pelas } \\
\text { companhias. }\end{array}$ & $\begin{array}{l}\text { O artigo buscou en- } \\
\text { fatizar em sua pesquisa } \\
\text { os pilares ambiental e } \\
\text { social do TBL. Foram ev- } \\
\text { idenciados e adaptados } \\
\text { ao contexto brasileiro } \\
\text { itens avaliados pelo } \\
\text { Instituto Ethos, aprox- } \\
\text { imando as questões } \\
\text { sociais ao contexto } \\
\text { brasileiro que pode ser } \\
\text { diferente do que é apre- } \\
\text { sentado pela literatura } \\
\text { estrangeira; por fim o } \\
\text { estudo sugere que as } \\
\text { iniciativas ambientais in- } \\
\text { ternas possam estimular } \\
\text { continuamente a criação } \\
\text { de novos produtos e } \\
\text { aperfeiçoamento da } \\
\text { gestão ambiental. }\end{array}$ \\
\hline $\begin{array}{l}\text { Journal of Operations } \\
\text { and } \\
\text { Supply Chain Manage- } \\
\text { ment } \\
2011 \\
\text { Brasil } \\
\text { P.6. DALÉ, L. B. C.; } \\
\text { ROLDAN, L. B.; } \\
\text { HANSEN, P. B. }\end{array}$ & $\begin{array}{l}\text { Analysis of sustainability } \\
\text { incorporation by indus- } \\
\text { trial supply chain in Rio } \\
\text { Grande do Sul State } \\
\text { (Brazil). } \\
\text { Abordagem Qualitativa } \\
\text { (Pesquisa qualitativa } \\
\text { exploratória, estudo de } \\
\text { caso múltiplo). }\end{array}$ & $\begin{array}{l}\text { Analisar como } \\
\text { a sustentabili- } \\
\text { dade está sendo } \\
\text { incorporada } \\
\text { por empresas } \\
\text { focais industri- } \\
\text { ais em práticas } \\
\text { de cadeia de } \\
\text { suprimentos no } \\
\text { Estado do Rio } \\
\text { Grande do Sul, } \\
\text { Brasil. }\end{array}$ & $\begin{array}{l}\text { Dentre as empresas } \\
\text { analisadas, todas consid- } \\
\text { eraram o pilar econômi- } \\
\text { co da sustentabilidade } \\
\text { como o mais significa- } \\
\text { tivo em suas cadeias de } \\
\text { suprimento, apesar do } \\
\text { pilar ambiental estar } \\
\text { conquistando grande } \\
\text { relevância, enquanto } \\
\text { que o pilar social vem se } \\
\text { desenvolvendo pouco a } \\
\text { pouco. }\end{array}$ \\
\hline
\end{tabular}

Fonte: Dados da pesquisa (2017), elaborado pelos autores (Recife, 2017).

A análise dos resultados revelou que dos seis artigos investigados, quatro foram publicados no Journal of Operations and Supply Chain Management, o que 
reforça uma tendência de internacionalização da academia brasileira e consequentemente das pesquisas em Supply Chain Management Sustainability, cuja temática vem sendo discutida predominantemente entre os pesquisadores, estudantes e ex-estudantes de mestrado e doutorado oriundos das regiões Sudeste (São Paulo) e Sul (Paraná e Rio Grande do Sul), com destaque para os grupos de pesquisa vinculados aos programas de pós-graduação em administração da Universidade Federal do Rio Grande do Sul e Fundação Getúlio Vargas/EAESP.

Em suma, os artigos foram incluídos com base no background teórico da Sustainable Supply Chain Management com foco na questão social. Entre as questões sociais discutidas nos artigos estão: 1) benefícios sociais sobre os valores humanos (qualidade de vida, igualdade de acesso aos serviços sociais, distribuição de renda, entre outros); 2) práticas de responsabilidade social empresarial (balanço social, código de ética, entre outros); e 3) aspectos gerais da SSCM e as questões sociais. Para melhor apresentação do conteúdo abordado nos artigos, foi proposta a apresentação dos resultados em temas onde p é abreviação do periódico selecionado.

Tema 1: Benefícios sociais sobre os valores bumanos.

P.1. As empresas pesquisadas apontam a questão da falta de conscientização do usuário final, com relação à separação de materiais, como uma barreira da Logística Reversa (LR). Para que a LR seja efetiva é necessário o engajamento da população com relação às práticas sustentáveis.

\section{Tema 2: Práticas de responsabilidade social empresarial.}

P.2. Quanto ao discurso do social, a empresa se intitula "socialmente responsável". São utilizados instrumentos como: 1) A política de relação com fornecedores, 2) Código de Ética e de Conduta da empresa. Sobre as ações sociais, são executadas por meio de uma fundação criada para gerir e direcionar o investimento social. Para a prática social, são executadas auditorias periódicas. Fontes externas à empresa denunciaram relatos de trabalho escravo contrários ao balanço social. 
P.5. O modelo teórico das pressões proposto pelo artigo apresenta os seguintes construtos: pressões governamentais, pressões do cliente, pressões dos fornecedores e aspectos internos da organização. Para medir as práticas sociais, o trabalho baseou-se em Ageron et al. (2011); (2011); Paulraj (2011);Paulraj (2011); Hollos, Blome e Foerstl (2011), but it was adapted to a Brazilian context via social indicators research established by Ethos Institute (2013) in their questionnaire for implementation and evaluation of politics and responsibility actions on Brazilian companies. Hollos, Blome e Foerstl (2011). Além da menção destes autores, para fins de adaptar as práticas sociais ao contexto brasileiro, foram utilizados 23 indicadores sociais do Instituto Ethos (2013). Devido a problemas no modelo, o construto pressões governamentais foi excluído. Os setores investigados no Estado de Minas Gerais estavam representados pelos setores de bebidas e laticínios (32\%), alimentos (32\%) e químicos e farmacêuticos (36,6\%). Entre os entrevistados 30\% ocupavam cargos de supervisão ou gerenciamento na área de ambiental, outros $15 \%$ pertenciam à área de produção ou engenharia ambiental, ambas as áreas estão relacionadas às áreas de operações e meio ambiente. Ao final dos testes o modelo foi considerado válido e com um nível aceitável de ajuste, incluindo 4 construtos com 16 indicadores. O estudo sugere estímulos contínuos, por meio das iniciativas ambientais internas para criação de novos produtos e aperfeiçoamento da gestão ambiental.

P.6. As empresas focais das cadeias de suprimento pesquisadas já desenvolviam práticas sustentáveis, contudo a disseminação efetiva dessas práticas far-se-á segundo uma lógica de aprendizagem e incorporação progressiva ao longo do tempo dos requisitos da sustentabilidade entre os stakeholders envolvidos nas cadeias de suprimento. Estes requisitos são condição para o sucesso pleno das cadeias de suprimento.

Tema 3: Aspectos gerais da SSCM e as questões sociais.

P.3. De um total de 124 publicações apenas 12 artigos consideram todas as dimensões da sustentabilidade. Foram identificados 47 artigos relacionados à sustentabilidade e SCM. Quanto a dimensão social estão em destaques os temas relacionados 
ao "envolvimento da comunidade", "comportamento socialmente responsável" e "consciência de gênero". A dimensão social ainda não está identificada seriamente como uma fonte de criação de valor dentro das cadeias de suprimentos no Brasil. É necessário compreender as publicações em relação a todas as dimensões da sustentabilidade.

P.4. Das três principais conferências (SIMPOI, ENGEMA e EnANPAD) sobre tema gestão sustentável da cadeia de suprimentos foram extraídos 37 trabalhos. Dentre as revistas selecionadas foram identificados 7 artigos. A análise revelou a proeminência da sustentabilidade como um tópico bastante separado, sem uma maior ênfase no próprio conceito da cadeia de suprimentos. Diante da abordagem metodológica utilizadas nos trabalhos há um destaque para os estudos de caso (26 ou 59,09\%), pesquisa conceitual/teórica e revisão da literatura (15 ou 34,09\%) e pesquisas (3 ou 6,82\%).

Nota-se que a abordagem TBL é com frequência utilizada nos artigos investigados, objetivando classificar os aspectos da sustentabilidade (ambiental, social e econômica). Apesar dos estudos confirmarem em suas amostras que a totalidade dos artigos estava classificada na dimensão econômica, enfatizando questões relacionadas à transformação do negócio para a sustentabilidade, constatou-se que a ênfase estaria sobre os aspectos econômicos.

\section{CONSIDERAÇÕES FINAIS}

Com vistas à discussão de como as empresas podem diminuir os problemas ambientais ou sociais nas cadeias de suprimento, de modo a torná-las verdadeiramente sustentáveis, a partir da diminuição dos problemas ambientais e sociais associados, os autores Montabon, Pagell e Wu (2016) analisaram as principais fraquezas das lógicas anteriores e desenvolveram uma lógica ecologicamente dominante, onde os interesses ambientais e sociais substituem os interesses econômicos. Essa lógica implica que as empresas passem a se preocupar primeiro com as questões ambientais e em seguida pensar nas questões econômicas, ou seja, as verdadeiras cadeias sustentáveis são raras, na melhor das hipóteses são analisadas as práticas existentes 
para determinar se estas estão contribuindo para redução dos danos ambientais e sociais. Para Touboulic e Walker (2015) os caminhos promissores para o futuro desenvolvimento da SSCM ficaria em torno da dimensão social e humana da sustentabilidade.

A revisão integrativa da literatura contribuiu para caracterização dos estudos em SSCM, na medida em que evidenciou os principais autores e co-autores brasileiros e estrangeiros que estão trabalhando a temática da SSCM com foco nas questões no contexto brasileiro. É importante salientar que a comunidade científica nacional tem buscado esforços de internacionalização da sua produção científica, tendo em vista que dos seis artigos examinados, quatro estão escritos na língua inglesa e submetidos em periódico internacional.

Observou-se que os estudos em SSCM no Brasil estão alinhados aos desafios colocados pela comunidade científica internacional no que diz respeito à tentativa de discutir a importância das questões sociais na cadeia de suprimento, em termos de risco atribuído à imagem da empresa advinda das pressões exercidas pelas partes interessadas externas em prol do bem-estar social da comunidade à qual a empresa exerce influência em termos de benfeitorias ou danos sociais.

A revisão integrativa da literatura aponta para a necessidade de serem discutidos os efeitos das questões sociais em cadeias de suprimento, visto que o desenvolvimento só ocorrerá com difusão de novas investigações e pesquisas a serem materializadas com a divulgação em periódicos nacional e internacional.

\section{REFERÊNCIAS}

ALVES, A. P. F.; SILVA, M. E. Reflexões Empíricas Sobre a Dimensão Social da Sustentabilidade em Cadeias de Suprimento: O que Precisa Mudar? Revista de Gestão Ambiental e Sustentabilidade-GeAS, v. 6, n. 1, p. 13-25, 2017.

ANDRADE, P. C. F.; TOURINHO, F. S. V.; CARVALHO JÚNIOR, P. M. Competências no processo de formação do enfermeiro para o cuidado ao envelhecimento: revisão integrativa. Texto \& Contexto Enfermagem, v. 25. n. 4, p. 1-9, 2016. 
BERNARDES, I. A. Irmãos saudáveis de criança com câncer: revisão integrativa da literatura. Espaço para a Saúde-Revista de Saúde Pública do Paraná, v. 16, n. 4, p. 98-108, 2016.

CARTER, C. R.; ROGERS, D. S. A framework of sustainable supply chain management: moving toward new theory. International journal of physical distribution \& logistics management, v. 38, n. 5, p. 360-387, 2008.

CARVALHO, A. P.; BARBIERI, J. C. Inovações socioambientais em cadeias de suprimento: um estudo de caso sobre o papel da empresa focal. RAI Revista de Administração e Inovação, v. 10, n. 1, p. 232-256, 2013.

COLBARI, A. Análise de Conteúdo e a Pesquisa Empírica Qualitativa. In: SOUZA, E. (Org.). Metodologias e analíticas qualitativas em pesquisa organizacional: uma abordagem teórico-conceitual - dados eletrônicos. Vitória: EDUSC, 2014, p. 241-271.

COOPER, H. M. Scientific guidelines for conducting integrative research reviews. Review of educational research, v. 52, n. 2, p. 291-302, 1982.

COOPER, H. M. Integrating research: A guide for literature reviews. SagePublications,Inc, 1989.

ELKINGTON, J. Cannibals with forks: the triple bottom line of 21st century business [reprint]. Oxford: Capstone, 2002.

FRANÇA, A. B.; LIMA, G. S.; KUSUMOTA, L.; MARQUES, S. Instrumentos de avaliação da qualidade de vida do idoso com Alzheimer: revisão integrativa da literatura. Revista Eletrônica de Enfermagem, v. 18, 2016.

GANONG, L. H. Integrative reviews of nursing research. Research in nursing \& health, v. 10, n. 1, p. 1-11, 1987.

LINTON, J. D.; KLASSEN, R.; JAYARAMAN, V. Sustainable supply chains: An introduction. Journal of operations management, v. 25, n. 6, p. 1075-1082, 2007.

MOHER, D.; SHAMSEER, L.; CLARKE, M.; GHERSI, D.; LIBERATI, A.; PETTICREW, M.; STEWART, L. A. Preferred reporting items for systematic review and meta-analysis 
protocols (PRISMA-P) 2015 statement. Systematic reviews, v. 4, n. 1, p. 1, 2015.

MONTABON, F.; PAGELL, M.; WU, Z. Making sustainability sustainable. Journal of Supply Chain Management, v. 52, n. 2, p. 11-27, 2016.

MOREIRA, M. A. D. M.; LUSTOSA, A. M.; DUTRA, F.; OLIVEIRA. B. E.; BATISTA, J. B. V.; DUARTE, M. C. S. Políticas públicas de humanização: revisão integrativa da literatura. Ciência \& Saúde Coletiva, v. 20, n. 10, p. 3231-3242, 2015.

PAGELL, M.; WU, Z. Building a more complete theory of sustainable supply chain management using case studies of 10 exemplars. Journal of supply chain management, v. 45, n. 2, p. 37-56, 2009.

ROMAN, A. R.; FRIEDLANDER, M. R. Revisão integrativa de pesquisa aplicada à enfermagem. CogitareEnfermagem, v. 3, n. 2, 1998.

SEURING, S. A. Assessing the rigor of case study research in supply chain management. Supply Chain Management: An International Journal, v. 13, n. 2, p. 128137, 2008.

SEURING, S. A.; MÜLLER, M. From a literature review to a conceptual framework for sustainable supply chain management. Journal of cleaner production, v. 16, n. 15, p. 1699-1710, 2008.

SILVA, M. E.; NASCIMENTO, L. F. (Re) pensando a intersecção entre sustentabilidade e cadeia de suprimento. Revista ESPACIOS, v. 37, n. 4, 2016.

SILVA, M. E. Perspectivas para o estudo de sustentabilidade em cadeias de suprimento: Uma discussão a partir da visão de especialistas. Revista Metropolitana de Sustentabilidade, v. 7, n. 1, p. 91, 2017.

SOUZA, M. T.; SILVA, M. D.; CARVALHO. R. Revisão integrativa: o que é e como fazer. Einstein, v. 8, n. 1 Pt 1, p. 102-6, 2010.

TOUBOULIC, A.; WALKER, H. Theories in sustainable supply chain management: a structured literature review. International Journal of Physical Distribution \& Logistics Management, v. 45, n. 1/2, p. 16-42, 2015. 
URSI, E. S. Prevenção de lesões de pele no perioperatório: revisão integrativa da literatura. 2005. Dissertação (Mestrado em Enfermagem Fundamental) - Escola de Enfermagem de Ribeirão Preto, Universidade de São Paulo, Ribeirão Preto, 2005.

YAWAR, S. A.; SEURING, A. S. Management of social issues in supply chains: a literature review exploring social issues, actions and performance outcomes. Journal of Business Ethics, v. 141, n. 3, p. 621-643, 2017.

Recebido em: 04/02/2018 Aceito em: 16/04/2018 